The Journal of Bone E Joint Surgery
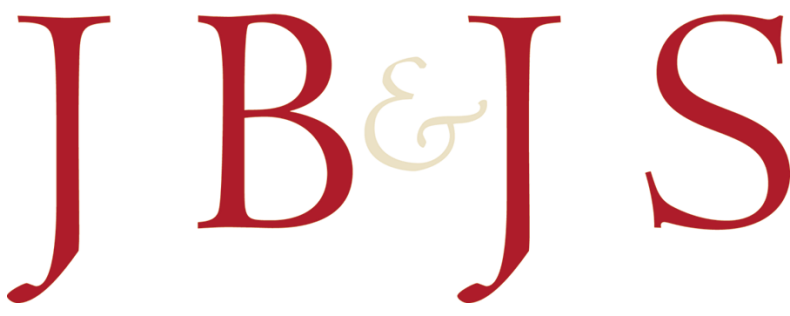

This is an enhanced PDF from The Journal of Bone and Joint Surgery

The PDF of the article you requested follows this cover page.

\title{
Chondrocyte Death Associated with Human Femoral Osteochondral Harvest as Performed for Mosaicplasty
}

J.S. Huntley, P.G. Bush, J.M. McBirnie, A.H. Simpson and A.C. Hall

J Bone Joint Surg Am. 2005;87:351-360. doi:10.2106/JBJS.D.02086

This information is current as of August 9, 2010

Supplementary Material

Reprints and Permissions

Publisher Information
http://www.ejbjs.org/cgi/content/full/87/2/351/DC1

Click here to order reprints or request permission to use material from this article, or locate the article citation on jbjs.org and click on the [Reprints and Permissions] link.

The Journal of Bone and Joint Surgery

20 Pickering Street, Needham, MA 02492-3157

www.jbjs.org 


\title{
Chondrocyte DeATH Associated with Human Femoral Osteochondral HaRvest as PERformed FOR MOSAICPLASTY
}

\author{
By J.S. Huntley, DPhiL(OxON), MRCS, P.G. Bush, PhD, J.M. McBirnie, FRCS, \\ A.H. SimpSON, DM(OXON), FRCS, AND A.C. HALL, PHD \\ Investigation performed at University of Edinburgh, Edinburgh, Scotland
}

\begin{abstract}
Background: Autologous osteochondral transfer is an option for the treatment of articular defects. However, there are concerns about graft integration and the nature of the tissue forming the cartilage-cartilage bridge. Chondrocyte viability at graft and recipient edges is thought to be an important determinant of the quality of repair. The purpose of the present study was to evaluate early cell viability at the edges of osteochondral grafts from ex vivo human femoral condyles.
\end{abstract}

Methods: Fresh human tissue was obtained from eleven knees at the time of total knee arthroplasty for the treatment of osteoarthritis. Osteochondral cylinders were harvested with use of a 4.5-mm-diameter mosaicplasty osteotome from regions of the anterolateral aspect of the femoral condyle that were macroscopically nondegenerate and histologically nonfibrillated. Plugs were assessed for marginal cell viability by means of confocal laser scanning microscopy.

Results: The diameter of the cartilaginous portion of the osteochondral plugs was a mean (and standard error of the mean) of $4.84 \pm 0.12 \mathrm{~mm}$ (as determined on the basis of three plugs). This value was approximately $300 \mu \mathrm{m}$ greater than the measured internal diameter of the osteotome. There was a substantial margin of superficial zone cell death (mean thickness, $382 \pm 68.2 \mu \mathrm{m}$ ), with $>99 \%$ cell viability seen more centrally (as determined on the basis of five plugs). Demiplugs were created by splitting the mosaicplasty explants with a fresh number-11 scalpel blade. The margin of superficial zone cell death at the curved edge was significantly greater than that at the site of the scalpel cut $(390.3 \pm 18.8 \mu \mathrm{m}$ compared with $34.8 \pm 3.2 \mu \mathrm{m} ; \mathrm{p}=0.0286)$. Similar findings were observed when the cartilage alone was breached and the bone was left intact, with the margin of superficial zone cell death being significantly greater than that obtained in association with the straight scalpel incision $(268 \pm 38.9 \mu \mathrm{m}$ compared with $41.3 \pm$ $13.4 \mu \mathrm{m} ; \mathrm{p}=0.0286$ ). The margin of superficial zone cell death showed no increase during the time-period between fifteen minutes and two hours after plug harvest. A mathematical approximation of the mosaicplasty region suggested that early cell death of this magnitude affects about one third of the superficial graft area.

Conclusions: The results of the present study suggest that mosaicplasty, while capable of transposing viable hyaline cartilage, is associated with an extensive margin of cell death that is likely to compromise lateral integration and articular reconstruction.

Clinical Relevance: The data suggest that there is a need to improve the plug-harvest technique, which may improve graft-recipient healing and clinical outcomes.

$\mathrm{O}$ steochondral grafting is an attractive concept because the bone can heal by creeping substitution and the articular cartilage can survive because of adequate diffusional nutrition. Furthermore, cartilage is a privileged immunological site for allografts because it is avascular and chondrocytes are shielded by extracellular matrix. Unfortunately, articular cartilage has minimal reparative capacity'.

Over the past two decades, there have been encouraging clinical reports concerning osteochondral allografts $s^{2}$, lateral patellar autologous grafting for the treatment of large defects at the knee ${ }^{3}$, autologous chondrocyte implantation ${ }^{4,5}$, and autologous osteochondral transfer (mosaicplasty) ${ }^{6-8}$. Mosaicplasty is an option for the treatment of smaller articular defects, especially those due to trauma or osteochondritis dissecans ${ }^{6-8}$. The early results of one randomized, controlled trial favored autologous chondrocyte implantation over autologous trans- 
The Journal of Bone \& JOINT SURgery • JBIS. ORG VOLUME 87-A · NUmber 2 - FEBRUARY 2005
Chondrocyte Death Associated with Human Femoral Osteochondral Harvest as Performed for Mosaicplasty fer ${ }^{5}$. However, the results of another trial (involving secondlook biopsies) were more equivocal, suggesting that fibrocartilage is the predominant repair tissue following autologous chondrocyte implantation ${ }^{8}$.

Hyaline cartilage has a complex avascular heterogeneous structure $^{9-11}$ in which chondrocytes constitute only $5 \%$ of the volume yet are solely responsible for matrix maintenance. There are many data concerning cartilaginous wounding and the healing response $e^{9,11}$. Partial-thickness defects do not heal, and full-thickness defects repair with mechanically inferior fibrocartilage ${ }^{1}$. Chondrocyte viability is important in order for extracellular matrix to remain healthy because, as noted by Gilmore and Palfrey ${ }^{12}$, each chondrocyte has the potential to maintain a discrete maximum volume of matrix (a domain) surrounding it.

It has been well established that surgical maneuvers involve cell death at the wound edge ${ }^{13,14}$, and chondrocyte death is ultimately associated with degeneration of the surrounding matrix. Recent whole-animal experiments demonstrated a loss of chondrocytes from the cartilage bordering the wound edge of partial-thickness defects that had been generated with a custom-built planing instrument ${ }^{15}$. Trephine wounding of bovine articular cartilage explants induced cell death over several days ${ }^{16}$. On the basis of ultrastructural and TUNEL (Tdt-mediated biotin-dUDP nick-end labeling) analyses, it was suggested that cell death was at least partially attributable to apoptosis ${ }^{16}$. Trephine wounding of immature bovine cartilage explants that had been harvested off the bone was associated with a band of cell death. Microautoradiography showed little isotope incorporation ${ }^{14}$ in this zone of death, suggesting that there was no new matrix synthesis or proliferation in this zone. In addition, the mechanical impact associated with osteochondral tamping into predrilled osseous holes causes superficial zone cell death ${ }^{17}$. Studies on the pathological effects of impact have shown cell death colocalizing with articular surface $\mathrm{cracks}^{18}$, mixed necrotic and apoptotic features ${ }^{19}$, chondrocyte apoptosis ${ }^{20}$, and glycosaminoglycan release ${ }^{20}$.

Hyaline cartilage is capable of surviving transfer. However, after grafting, an absence of matrix-producing cells in the region of the cartilage-cartilage interface makes integrative cartilage repair unlikely ${ }^{13,14}$. Seams of mechanically inferior tissue or gaps between grafts may affect joint congruency and are likely to be a starting point for further degeneration ${ }^{8}$. Chondrocyte viability at the edge is likely to be a determinant of long-term success. However, examination of the effect of osteochondral surgical procedures on graft-edge viability, especially in human tissue, has been very limited ${ }^{1,14}$.

The choice of method for the study of cell viability is crucial. In contrast with conventional fixation, sectioning, and histological analysis, confocal laser scanning microscopy allows three-dimensional visualization of living cells in their native extracellular matrix and quantification of living and dead cells. It also permits serial optical imaging and three-dimensional reconstruction. The same volume of tissue can be imaged over time and from more than one perspective. For example, cartilage blocks examined from a superficial perspective subsequently can be examined transversely for fibril- lation. Confocal laser scanning microscopy therefore confers considerable advantages over traditional microscopy.

The purpose of the present study was to use confocal laser scanning microscopy in association with fluorescent indicators to determine early cell viability at the human osteochondral graft edge.

\section{Materials and Methods \\ Biochemicals}

B iochemicals were obtained from Sigma (Poole, Dorset, Bunited Kingdom), unless otherwise stated. The culture medium was serum-free Dulbecco modified Eagle medium (DMEM) with N-2-hydroxyethylpiperazine- $\mathrm{N}^{\prime}$-2-ethane sulphonic acid (HEPES) at $25 \mathrm{mM}$. CellTracker Green (5chloromethylfluorescein diacetate; CMFDA) and propidium iodide (PI) were obtained from Molecular Probes (Eugene, Oregon); stock solutions were propidium iodide (1-mM; aqueous) and CMFDA (2.15-mM; dimethyl sulfoxide [DMSO]). Formaldehyde solution (10\% volume per volume in normal saline solution; $\mathrm{pH}$ 7.3) was obtained from Fisher Scientific (Leicestershire, United Kingdom).

\section{Ethical Approval}

Ethical approval for the present study was obtained from the Fife Acute Hospitals NHS Trust (Scotland) Ethics Committee. Additionally, informed consent was obtained from patients undergoing total knee arthroplasty.
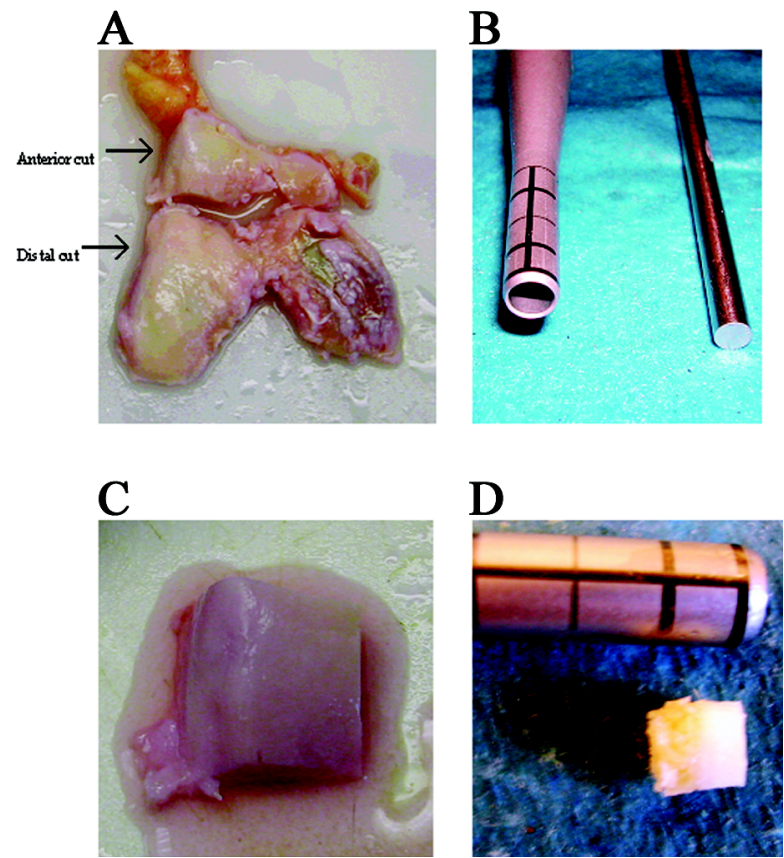

Fig. 1

Images depicting osteochondral harvesting as performed for mosaicplasty. A, Anterior and distal cuts made during total knee replacement. $B$, Circular osteotome (internal diameter, $4.5 \mathrm{~mm}$ ) and plug remover.

C, Osteochondral explant measuring approximately $15 \mathrm{~mm} \times 15 \mathrm{~mm}$.

$D$, Osteochondral plug with clear cartilage and bone definition. 
The JOURnal of BOnE \& JOINT Surgery · JBJS.ORG VOLUME 87-A · NUmber 2 - FEBRUARY 2005
Chondrocyte Death Associated with Human Femoral Osteochondral Harvest as Performed for Mosaicplasty

Fig. 2

Projectional image of a human osteochondral plug surface, fixed two hours after harvest, showing a zone of circumferential cell death. The plug had been exposed to fluorescent dyes for thirty minutes before fixation. Propidium iodide stains the nuclei of dead cells red, and CMFDA stains the cytoplasm of live cells green. Each square is $921.4 \mu \mathrm{m}$ in length.
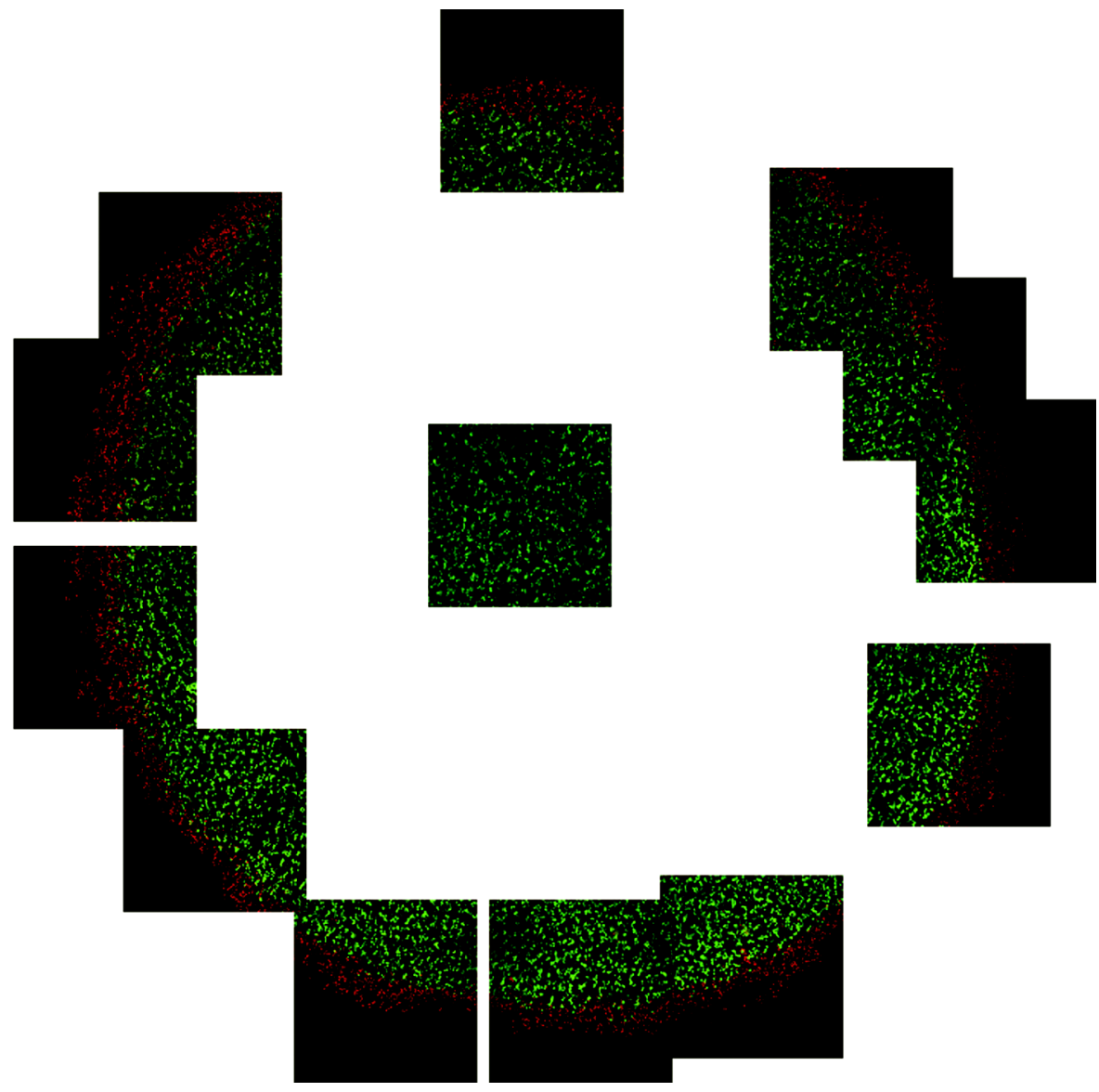

\section{Human Osteochondral Explants}

Resection specimens from patients undergoing total knee arthroplasty for the treatment of osteoarthritis were placed immediately into DMEM and were refrigerated overnight at $4^{\circ} \mathrm{C}$ (analogous to the temperature used for fresh osteochondral allografts $^{21}$ ) before use on the subsequent day. The lateral condylar area from the anterior cut for total knee arthroplasty (Fig. 1, A), analogous to the region used during mosaicplasty $^{21,22}$, was used as a source for osteochondral plugs. A specimen was used only if there was no macroscopic evidence of fibrillation, wear lines, or degeneration in the relevant region. The rationale behind the use of this tissue is based partly on evidence documenting the similarity between pristine human cartilage and macroscopically nondegenerated cartilage specimens resected from osteoarthritic knees ${ }^{22}$. Of the twentyfive knees examined, only eleven (from patients ranging from fifty-three to seventy-nine years of age) had a lateral condyle that was suitable for this study. Plugs were harvested with use of a sterile technique, as utilized for tissue culture. A circular mosaicplasty osteotome with a 4.5-mm internal diameter (Fig. $1, B)$ was used, according to the mosaicplasty harvest technique, within twenty-four hours after the original operation. The osteotome was applied perpendicular to the articular surface, and the cut was deepened with use of a light (230-g) toffee hammer to harvest a bone-cartilage composite plug measur- ing 7 to $9 \mathrm{~mm}$ in length. As during surgery, slight toggling of the osteotome was used to allow dislodging. For experiments in which tissue had to be preloaded with dye (see section entitled Dynamics of Cell Death) or in which only the cartilage was breached (see section entitled Margin of Cell Death When Bone Not Breached), an osteochondral cuboid (Fig. 1, C) was trimmed with use of a Stanley knife and then was subjected to the plug-harvesting technique in a similar way. No rotational movement was made during the harvesting procedure; all cuts (including those performed with a number-11 scalpel blade with its straight blade configuration) were made in pushthrough mode, with the direction of the cutting force applied solely perpendicular to the blade edge (analogous to the mode of cutting during mosaicplasty). The plug (Fig. 1, D) was removed from the inside of the circular chisel with use of an insert set against the osseous surface. The articular surface was kept wet with DMEM throughout the procedure as articular chondrocytes are known to be vulnerable to the effects of drying $^{23}$. Care was taken not to subject the hyaline surface to any abrasive or additional force other than those associated with the harvesting procedure. Because of concerns about blade sharpness, virgin tools were used when possible and no mosaicplasty instrument was used to harvest more than six plugs (Fig. 1, D). This number is well within the operating limit of instrument use. The cartilaginous portion of three 
The Journal of BOne \& JOINT SURGERY • JBJS.ORG VOLUME 87-A · NUmber 2 - FEBRUARY 2005
Chondrocyte Death Associated with Human Femoral Osteochondral Harvest as Performed for Mosaicplasty plugs and the internal diameter of the mosaicplasty chisel were measured with use of Vernier calipers (British Aerospace, Bristol, United Kingdom) with an accuracy of $\pm 10 \mu \mathrm{m}$.

\section{Fluorescent Contrast Media}

Fluorescent contrast media have been used previously to document cell viability and death differentially in cartilage explants $^{11,14,24}$. CMFDA is a membrane-permeant dye that is cleaved by intracellular esterases to produce a fluorescent and membrane-impermeant product. The cytoplasm of viable cells is marked as green ${ }^{25}$. Conversely, propidium iodide is a charged molecule that is capable of crossing cell membranes only if they are damaged. Propidium iodide stains the nuclei of dead cells red. Tissue was incubated with contrast medium concentrations that were chosen to optimize imaging parameters ( 10.75 to $21.5 \mu \mathrm{M}$ for CMFDA and $5 \mu \mathrm{M}$ for propidium iodide).

\section{Incubation and Fixation}

For most experiments, plugs were incubated at $37^{\circ} \mathrm{C}$ for 120 minutes, with exposure to propidium iodide $(5 \mu \mathrm{M})$ and $\mathrm{CM}-$ FDA $(10.75 \mu \mathrm{M})$ for the final thirty minutes. At the end of the incubation period, plugs were washed in DMEM and were transferred to $10 \%$ formalin (volume per volume) in saline solution. They were stored at $4^{\circ} \mathrm{C}$ and, after passage to $70 \%$ ethanol (volume per volume), they were analyzed in water (at $21^{\circ} \mathrm{C}$ ) on the subsequent day. However, for the time-course experiments, explants were exposed to propidium iodide (5 $\mu \mathrm{M})$ and CMFDA $(21.5 \mu \mathrm{M})$ in DMEM at $37^{\circ} \mathrm{C}$ for fifteen minutes before incisions were made with the mosaicplasty osteotome and scalpel. They were then transferred for confocal laser scanning microscopy and were maintained in DMEM, with contrast media at the same concentration, at $21^{\circ} \mathrm{C}$ over the time-course indicated.

\section{Microscopy}

An upright Zeiss Axioskop LSM 510 confocal laser scanning microscope was fitted with an objective $(\times 10$ dry $)$ to acquire images of in situ articular chondrocytes labeled with fluorescent dyes. A multitrack protocol involving argon and $\mathrm{HeNe}$ (helium-neon) excitation allowed separation of the fluorescence emitted from CMFDA (which stained the cytoplasm of live cells green) and propidium iodide (which stained the nuclei of dead cells red). CMFDA and propidium iodide were subjected to excitation wavelengths $\left(\mathrm{EX}_{\lambda}\right)$ of 488 and $543 \mathrm{~nm}$, respectively, with use of bandpass and long pass filters to measure emission ( 500 to $550 \mathrm{~nm}$ and $>560 \mathrm{~nm}$, respectively). Cartilage was viewed from both surface and transverse perspectives, thereby allowing for the imaging of all zones in detail throughout the full cartilage depth. Laser power, detector gain, and sensitivity were adjusted to obtain optimal images without excessive bleaching or saturation. Optical sections were obtained at approximately $10-\mu \mathrm{m}$ intervals over a depth of $170 \mu \mathrm{m}$.

\section{Image Analysis}

Images were overlaid and projected over appropriate depths with use of the Zeiss Image Browser (Hertfordshire, United Kingdom). Mean margins of cell death were calculated with use of measurements of the plug perimeter and the associated sector area of cell death, according to the equation:

$$
d=1000 \times r-\left[r^{2}-(2 . r . \mathrm{A} / p)\right]^{1 / 2}
$$

where $d$ is the margin of cell death (in $\mu \mathrm{m}$ ), $\mathrm{A}$ is the measured area (in $\left.\mathrm{mm}^{2}\right), r$ is the radius of the plug (in $\mathrm{mm}$ ), and $p$ is the measured perimeter (in $\mathrm{mm}$ ). For the $4.5-\mathrm{mm}$ harvester, the actual plug diameter was $4.84 \mathrm{~mm}$ (and the radius was 2.42 $\mathrm{mm}$ ) (see Results section). Values were recorded from multiple images for all tissues to ensure imaging of the plug circumference in its entirety.

\section{Tissue Grading}

Anterolateral femoral condylar tissue was used only if there was no macroscopic evidence of degeneration, fibrillation, or wear lines ${ }^{24}$. The samples were confirmed as being focally nondegenerate (grade 0 according to the system described by Bush and $\mathrm{Hall}^{24}$ ) by means of microscopic transverse sectional imaging (confocal laser scanning microscopy; $\times 10$ objective) to ensure that all zones were without fibrillation or splitting on the basis of extracellular matrix autofluorescence and tissuestaining.

\section{Statistical Analysis}

Generally, data are given as the mean and the standard error of the mean. For measurements pertaining to the marginal zone of death, normality could not be assumed on the basis of the small number of observations. Therefore, where appropriate, nonparametric significance tests were used (GraphPad Prism; GraphPad Software, San Diego, California).
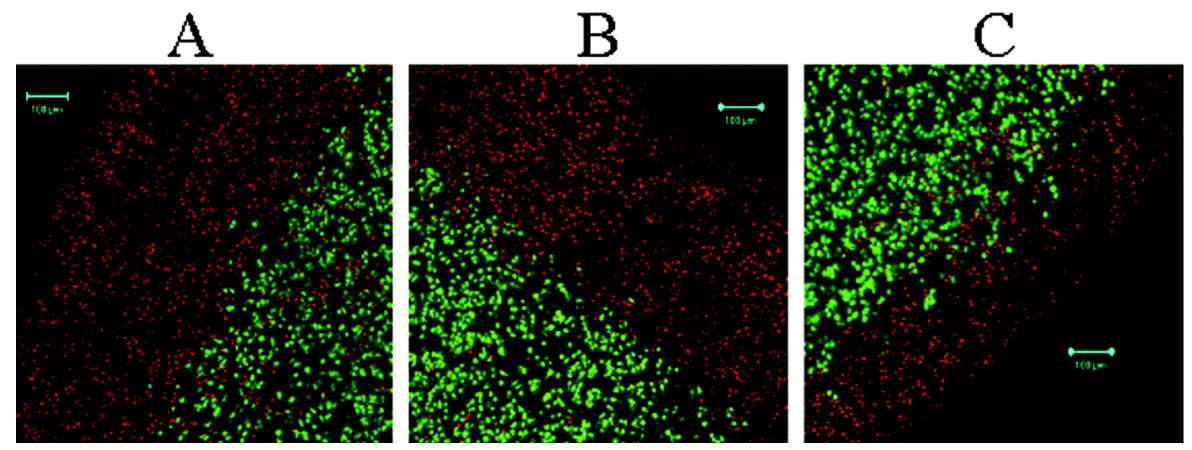

Fig. 3

Three representative projectional views (depth, $170 \mu \mathrm{m}$ ) of a plug surface, showing the heterogeneity of the marginal zone of cell death (red stain). Blue bar $=100 \mu \mathrm{m}$. 
The Journal of Bone \& JoInt SURGERy · JBJS.ORG Volume 87-A · Number 2 - February 2005
Chondrocyte Death Associated with Human Femoral Osteochondral Harvest as Performed for Mosaicplasty
Fig. 4

Representative projectional views of a human femoral demiplug that had been harvested as described and fixed after two hours of incubation, with exposure to contrast medium for the last thirty minutes. $A$, Projectional view (depth, $170 \mu \mathrm{m}$ ) showing the margins of cell death (red stain) associated with two types of cut (one made with a curved circular mosaicplasty osteotome and the other made with a straight sharp scalpel blade). Blue bar $=100 \mu \mathrm{m}$. B, Transverse projectional view (depth, 170 $\mu \mathrm{m}$ ) of a straight cut, across all zones, showing cell viability with minimal cell death (red stain). C, Transverse projectional view (depth, 170 $\mu \mathrm{m}$ ) of curved cut, showing cell death with minimal cell viability (green stain). For $B$ and $C$, each whole square is $921.4 \mu \mathrm{m}$ in length.
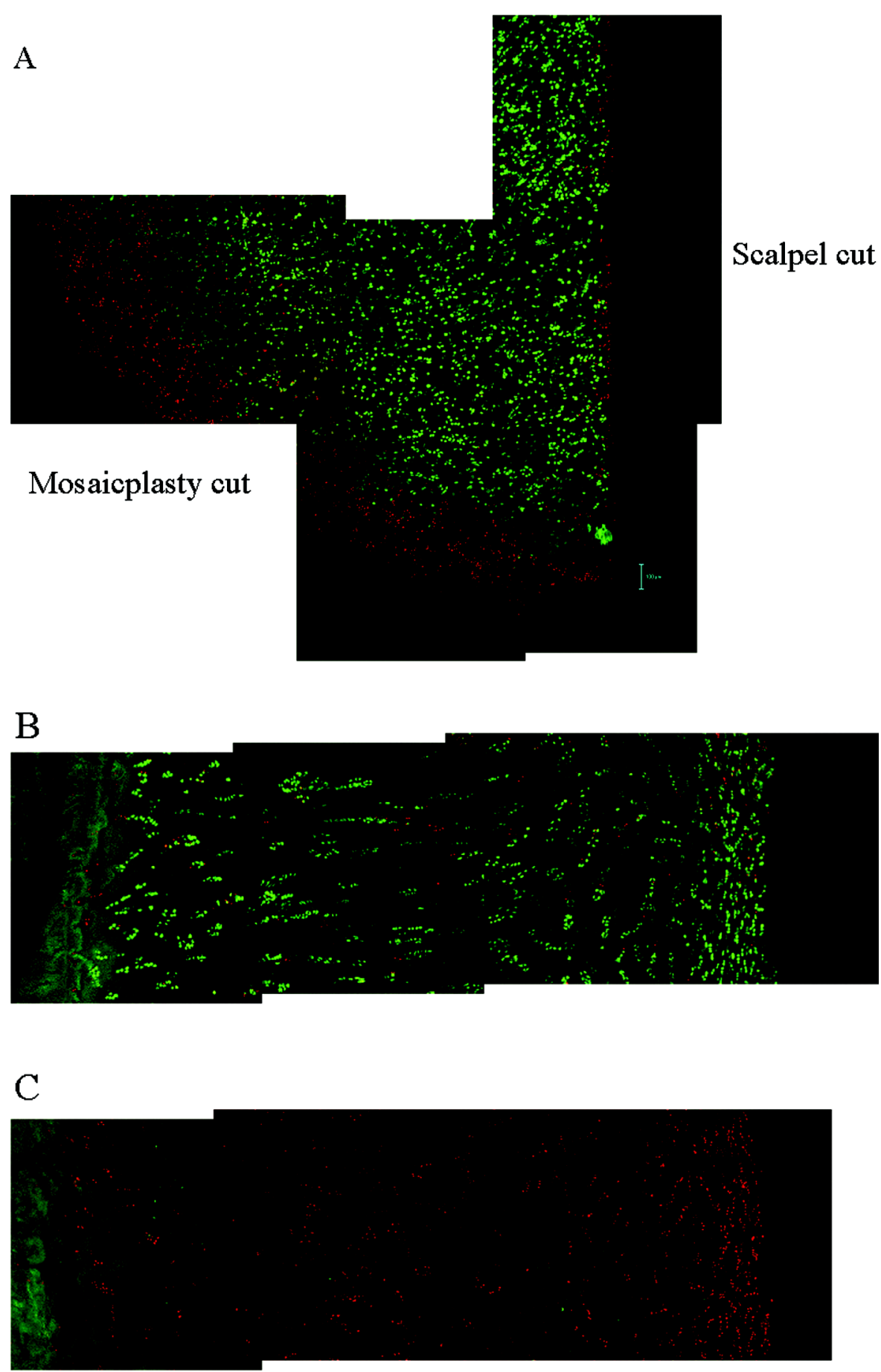

\section{Results}

\section{Caliper Measurements}

Titially, it was important to establish the precise dimensions of 1 the harvested plugs, both for subsequent analysis and to determine if the fixation procedure itself caused any shrinkage or swelling artifact. Osteochondral plugs were harvested from only macroscopically normal regions of the anterolateral aspect of the femoral condyle. The diameters of the cartilaginous por- tion of three plugs were measured with use of Vernier calipers. The internal diameter of the mosaicplasty chisel measured 4.54 $\mathrm{mm}$. The plug diameter was greater, measuring $4.84 \pm 0.12$ $\mathrm{mm}$ (mean and standard error of the mean) in DMEM and $4.84 \pm 0.03 \mathrm{~mm}$ when fixed and passed through alcohol to water. The diameter of the plugs was approximately $300 \mu \mathrm{m}$ larger than the internal diameter of the circular osteotome. Possible interpretations of these data are proposed in the Discussion section. 
The Journal of Bone \& JOINT SURGERY • JBIS.ORG VOLUME 87-A · NUmber 2 · FEBRUARY 2005
Chondrocyte Death Associated with Human Femoral Osteochondral Harvest as Performed for Mosaicplasty

\section{Definition of the Marginal Zone of Cell Death}

Analysis of five whole plugs (from three joints) showed a marginal zone of cell death with a mean thickness of $382 \pm 68.2$ $\mu \mathrm{m}$. Untraumatized areas at the center of the plugs demonstrated $>99 \%$ viability (Fig. 2 ). There was considerable intraplug heterogeneity with regard to the width of the marginal zone of cell death, as shown in a range of three-dimensional summation views over the most superficial $170 \mu \mathrm{m}$, the approximate penetrative limit of this technique (Fig. 3). When viewed from the side (again to a depth of approximately 170 $\mu \mathrm{m}$ ), the curved edge of four of the five plugs showed $>99 \%$ cell death throughout the full depth of cartilage, similar to the findings noted along the curved edge of the demiplugs in later experiments.

Four plugs, each of which had been cut from a different joint, were used for the demiplug experiments. In these experiments, the thickness of the zone of cell death along the circular cut (the cut that had been made with use of the mosaicplasty osteotome) was compared with that along a straight cut down the center of the plug (the cut that had been made with use of a fresh number-11 scalpel blade). From the superficial perspective, the thickness of the zone of cell death along the curved cut (mosaicplasty osteotome) was significantly greater than that along the straight cut (scalpel blade) $(390 \pm$ $18.8 \mu \mathrm{m}$ compared with $34.8 \pm 3.2 \mu \mathrm{m}$; $\mathrm{p}=0.0286$, MannWhitney test). A representative view that includes the junction of the curved and straight edges is shown in Figure 4, $A$. Representative side views of the straight (scalpel blade) and curved (osteotome) cuts are shown in Figure 4, $B$ and $C$, respectively. The osteotome cut produced $>99 \%$ cell death to the limits of laser penetration (approximately $170 \mu \mathrm{m}$ ) throughout the full depth of the cartilage.

\section{Margin of Cell Death When \\ Bone Not Breached}

It was important to address the potential problem posed by the force required to breach the subchondral bone in these samples as this force might be greater than that required in younger joints without degenerative disease. The mosaicplasty osteotome and number-11 scalpel blade incisions were made in four osteochondral explants, each from a different joint, with care being taken to penetrate the cartilage only (that is, not to transgress the subchondral bone) before blade removal. These explants subsequently were subjected to the same protocol as described in the Materials and Methods section (incubation at $37^{\circ} \mathrm{C}$ for two hours, with exposure to contrast medium for the last thirty minutes only) before fixation. The zone of cell death at the curved edge was significantly greater than that at the straight edge $(268 \pm 38.9 \mu \mathrm{m}$ compared with $41.3 \pm 13.4 \mu \mathrm{m}$; $\mathrm{p}=0.0286$, Mann-Whitney test). Figure 5 shows representative views from a single plug with hand-drawn overlays as used for measurements. Figure 5, $A$ and Figure 5, $B$ show the marginal zone of cell death at both the graft and donor edges. Figure 5, $C$ shows the zone of cell death along the number-11 scalpel blade cut. Figure 5, $D$ shows the intersection between the straight (scalpel) cut and the curved (osteotome) cut along with the associated zones of death. Figure 5, E shows the intersection of the two straight (scalpel) cuts in the center of the plug.

\section{Dynamics of Cell Death}

The dynamics of cell death were assessed over a two-hour
A

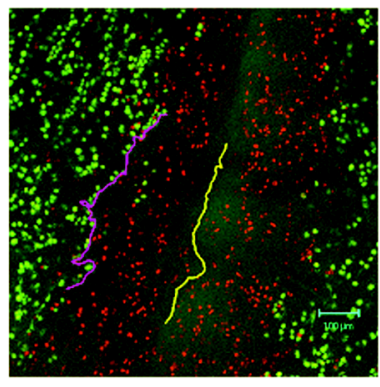

D

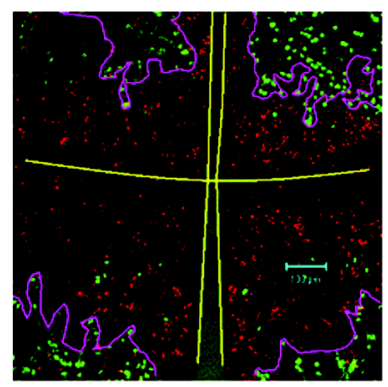

B

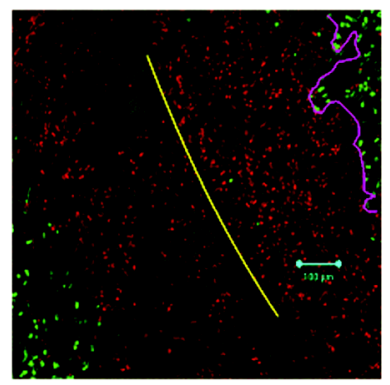

$\mathrm{E}$

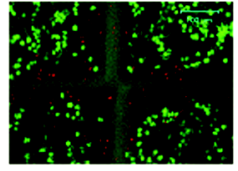

\section{$\mathrm{C}$}

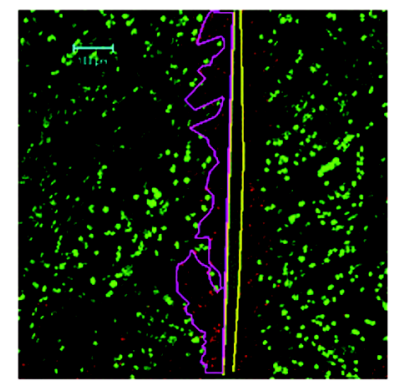

Fig. 5

Representative projectional surface views (depth, $170 \mu \mathrm{m}$ ) of an osteochondral explant that had been subjected to both mosaicplasty and scalpel blade cuts through cartilage only (i.e., without breaching the subchondral bone). After cutting, the explant was incubated for two hours before fixation, with exposure to contrast medium for the last thirty minutes. The yellow overlay marks the edge of the plug or scalpel cut. The pink overlay marks the junction of living and dead cells. $A$ and $B$, View of a mosaicplasty cut, showing associated margins of cell death in both plug and donor sites. $C$, View of a scalpel cut. $D$, View showing the intersection of a scalpel cut (vertical) and a mosaicplasty cut (horizontal). E, Intersection of two scalpel cuts in the center of the plug (no overlay shown). Blue bar $=100 \mu \mathrm{m}$. 
The JOURnAL OF BONE \& JOINT SURGERY • JBJS.ORG VOLUME 87-A · NUmber 2 · FEBRUARY 2005
Chondrocyte Death Associated with Human Femoral

Osteochondral Harvest as Performed for Mosaicplasty
Fig. 6

Illustrations depicting the dynamics of early marginal zone cell death. Osteochondral explants were exposed to $\mathrm{CM}$ FDA and propidium iodide for fifteen minutes at $37^{\circ} \mathrm{C}$ before demiplug harvest (mosaicplasty followed by splitting of the plug centrally with use of a scalpel blade). The explants were transferred for confocal laser scanning microscopy as fast as possible, with imaging used to quantify the thickness of the marginal zone of cell death in a single field of view over the subsequent two-hour period. A, Timecourse data from experiments on tissue from three patients, depicting the thickness of the marginal zone of cell death following a curved cut (mosaicplasty technique; filled symbols) and a straight cut (scalpel technique; cross-hatched symbols). $B$ and $C$, Representative images from one experiment with images made at successive time-points following the mosaicplasty cut $(B)$ and the scalpel cut $(C)$. The yellow overlay indicates the margin between live and dead cells. There was no progression of the margin of cell death over this time-course.

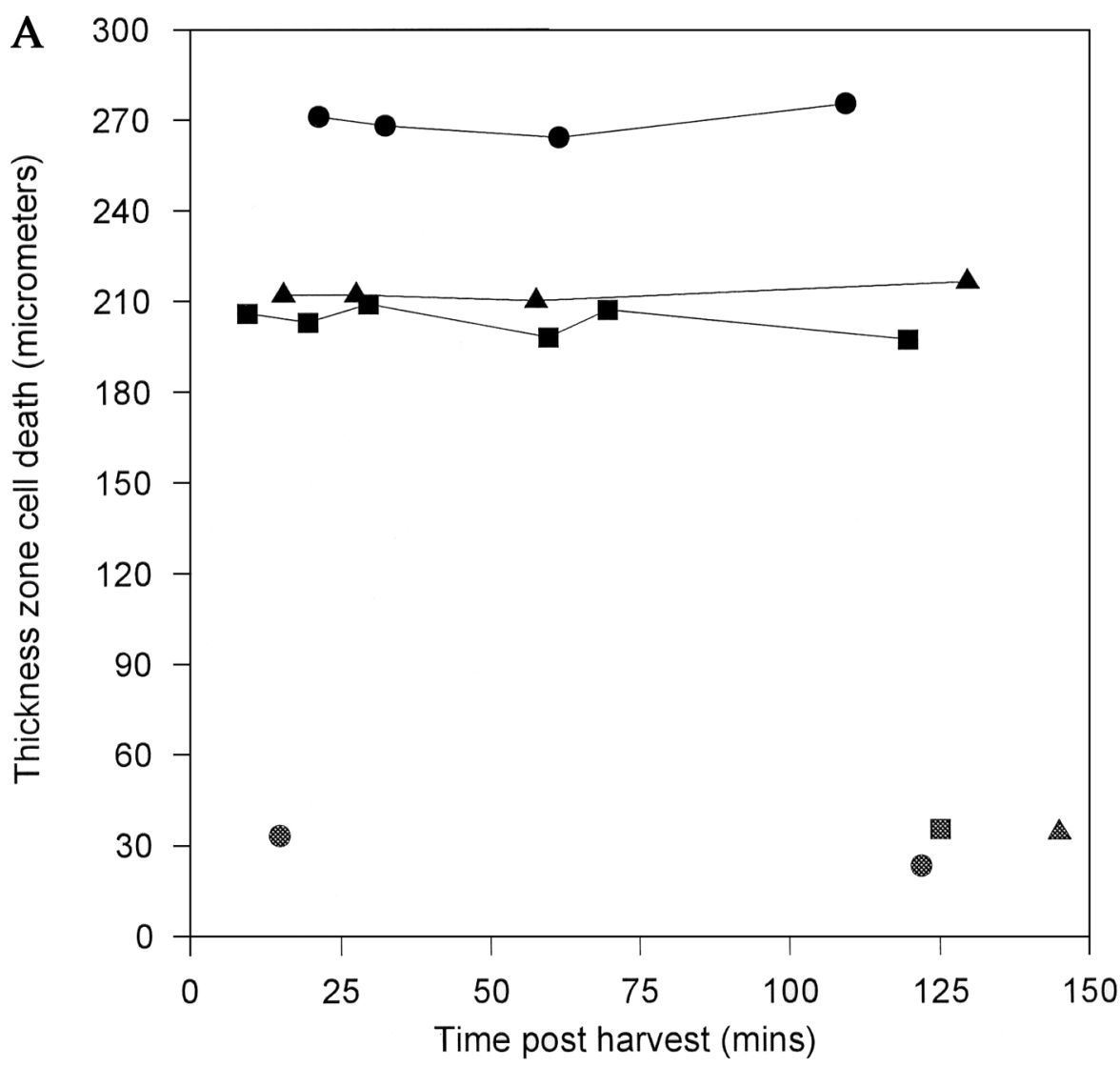

B

22 mins

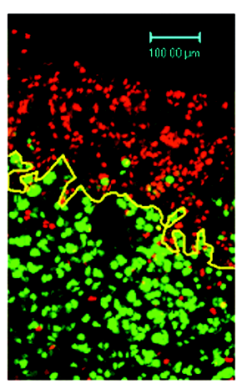

C

Scalpel (no. 11) edge

122 mins
33 mins
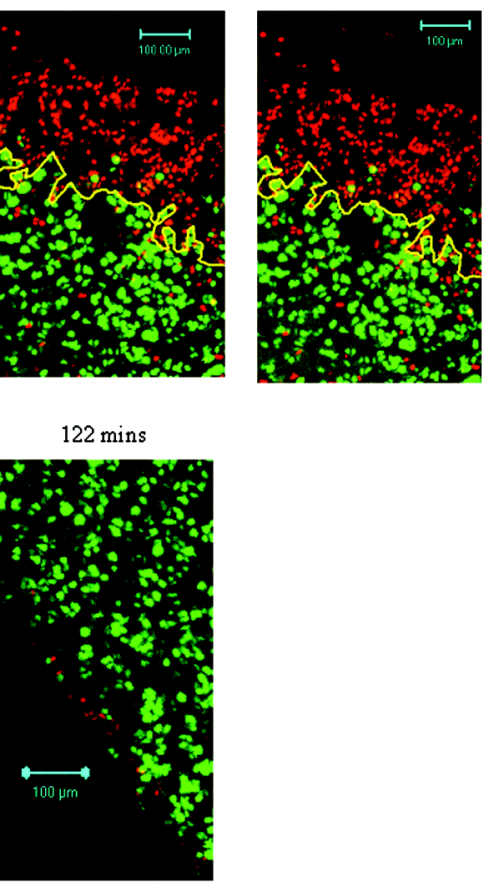

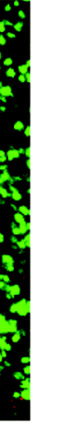

$62 \mathrm{mins}$

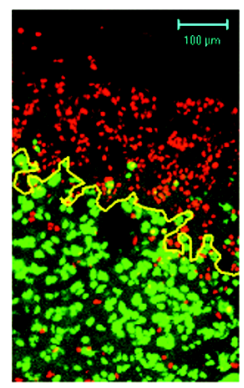

$110 \mathrm{mins}$

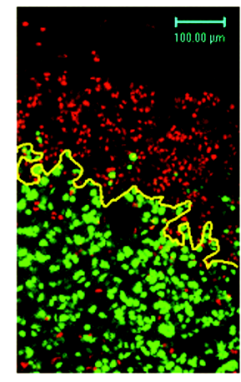

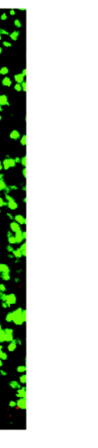

period after harvest. Explants were obtained with use of a and CMFDA for fifteen minutes before harvesting (see MateStanley knife and were preincubated with propidium iodide 
The Journal of Bone \& JOINT SURGERY • JBIS.ORG VOLUME 87-A · Number 2 - February 2005

described previously, to allow for a comparison of the thickness of the zone of marginal cell death along the curved (osteotome) and straight (scalpel) cuts. The graft edge zone of cell death showed no increase during the time-period between fifteen minutes and two hours after the incision. The results of three separate experiments are shown in Figure 6, $A$, with representative views from one experiment shown in Figure $6, B$ (depicting the zone along a curved cut made with use of a mosaicplasty osteotome) and Figure 6, $C$ (depicting the zone along a straight cut made with use of a fresh scalpel blade). These data indicate that from the earliest available time-point (fifteen minutes) to two hours after harvest with the mosaicplasty osteotome, there was no progression in the margin of cell death.

\section{Discussion}

Dristine human tissues for experimentation are in short sup1 ply. The bulk of the experimental work concerning cartilage wounding, integrative cartilage repair, and osteochondral grafting has involved animal models, and the results of such studies can only be extrapolated to the human situation with caution. We have chosen an alternative approach involving the use of macroscopically nondegenerate cartilage explants from joint surfaces harvested from patients undergoing total knee replacement for the treatment of osteoarthritis. The anterolateral aspect of the femoral condyle is often spared macroscopically from the arthritic process and correlates with the osteochondral harvest site for autografting (mosaicplasty). Macroscopically nondegenerate cartilage from patients undergoing knee arthroplasty for osteoarthritis previously has been found to be indistinguishable from normal human cartilage in terms of basic biochemical, metabolic, and histological parameters ${ }^{22}$.

Cell viability of this surface can be maintained at close to $100 \%$ if it is passed rapidly to DMEM, maintained at $4^{\circ} \mathrm{C}$, and used within twenty-four hours. Nevertheless, there are reservations about using tissue (1) from joints with established osteoarthritis, (2) from patients in this age-group, and (3) after refrigeration overnight (even if use occurs within twenty-four hours). Aging is known to affect cartilage and chondrocytes $^{9,26}$. Hangody and Fules ${ }^{6}$ found that the results of mosaicplasty were better in younger as compared with older patients and therefore proposed an upper age-limit of fifty years for this procedure. In the present study, although there was occasional chondrocyte clustering in some sections, the cartilage surface appeared normal macroscopically and transverse views of the articular surface did not demonstrate fibrillation or fissuring in the superficial zone (collagen autofluorescence) when observed with confocal laser scanning microscopy (Fig. 3, $B$ and $C$ ). It is not inconceivable that passage to DMEM and storage at $4^{\circ} \mathrm{C}$ overnight might have altered the mechanical sensitivity of chondrocytes. Nonetheless, there was a significant difference in the margin of cell death associated with mosaicplasty and scalpel cuts to the same depth. Furthermore, for fresh allograft procedures, storage at $4^{\circ} \mathrm{C}$ in Ringer's lactate for up to fortyeight hours is accepted practice ${ }^{21}$.
CHONDROCYTE DEATH ASSOCIATED WITH HUMAN FEMORAL Osteochondral Harvest as Performed for Mosaicplasty

A further reservation is that excessive force might be required to harvest plugs from this tissue. Subchondral sclerosis is a pathological feature of osteoarthritis, and therefore the force required to harvest osteochondral plugs from the joint resection specimens might be greater than that required at the time of mosaicplasty in younger knees. Although osteochondral harvesting was performed only on tissue that was grossly and histologically nondegenerate, it was nevertheless important to perform experiments in which only the cartilaginous tissue was breached and the plug was left in situ (Fig. 5). The margin of cell death was again significantly greater than that observed in association with a single scalpel cut to the same level, supporting the contention that it is trauma to the cartilage alone that is predominantly responsible for the observed marginal zone of cell death. It is emphasized that number-11 scalpel blade cuts constitute an internal negative control and that there is minimal marginal cell death in relation to such incisions. With respect to the thickness of the zone of marginal death, our findings contrast with those of Williams et al. $^{27}$, who used a coring drill and found no evidence of "thermal damage" at the periphery of $15-\mathrm{mm}$-diameter plugs when the periphery was compared with the central portion of the graft.

Conversely, damage to the superficial zone of the graft may exceed that indicated by early cell death in our model because further processes leading to cell death may only become manifest after the end of our time-course (that is, more than two hours after harvest). Also, during mosaicplasty, the graft surface is subjected to direct trauma when it is impacted into a predrilled hole. This tamping procedure is known to compromise chondrocyte viability ${ }^{17}$. Furthermore, the plugs used for our experiments were shorter (length, 7 to $9 \mathrm{~mm}$ ) than those obtained during mosaicplasty (length, 15 to $25 \mathrm{~mm})^{6-8}$, which minimized the trauma due to frictional contact on the inner aspect of the circular osteotome. The circumferential death indicates that the mosaicplasty construct lacks superficial zone hyaline cartilage-cartilage contact, suggesting a mechanically inferior construct in terms of spreading contact stresses.

There are a variety of modes through which surgical procedures can damage an articular surface. Cells near the cut surface may be exposed to a variety of insults, including compression, tension, and shear forces. These forces depend on parameters such as (1) the proximity of the blade (that is, the proximity of the cell to the cut surface), (2) the type of cutting edge, (3) the relation of the cutting edge to its supportive abrasive surface (the face of the blade), and (4) the angulation of the cutting edge and surface to planes in the extracellular matrix with which chondrocytes are associated. In the present study, both number-11 scalpel blades and mosaicplasty osteotomes were used solely in a push-through mode (i.e., with no sawing or rotatory movements) in order to minimize abrasive and shear forces.

In response to trauma, cell death may occur rapidly (within minutes) as a result of direct mechanical disruption, but it also may occur over a more prolonged period. It is interesting that there was no progression in the boundary of mar- 
The Journal of Bone \& JOINT SURGERY • JBIS.ORG VOLUME 87-A · NUmber 2 · FEBRUARY 2005
CHONDROCYTE DEATH ASSOCIATED WITH HUMAN FEMORAL Osteochondral Harvest as Performed for Mosaicplasty ginal cell death between fifteen minutes and two hours (Fig. 6). There was an absence of dye colocalization, suggesting leakage of the CMFDA product away from cellular remains showing nuclear-binding of propidium iodide. This finding supports our contention that punctate red-staining is indicative of cell death rather than sublethal injury. Tew et al. ${ }^{16}$ documented cell death over a longer time-course at a trephined wound edge in both mature and immature bovine cartilage explants; their data suggest cell death by a combination of apoptosis and necrosis. Our documentation of early chondrocyte death does not preclude other processes from occurring over a longer time-period. Indeed, an understanding of the mechanisms underlying early and late cell death may allow the development of cytoprotective strategies for the graft edge.

Not surprisingly, there was intraplug heterogeneity with regard to the width of the marginal zone of cell death (Fig. 3), which may have been due in part to the anisotropy of hyaline cartilage, as has been demonstrated in compression ${ }^{28}$, indentation stiffness ${ }^{29}$, and split-line studies of the femoral condyle ${ }^{30}$. The heterogeneity means that to derive an average thickness for the marginal zone of death, it is important to have either a random sampling procedure or the capability to image the entire plug or demiplug.

The approximate tenfold increase in thickness of the zone of cell death when the cartilage was incised with use of the mosaicplasty osteotome as opposed to the scalpel may have been related to a variety of features of the surgical implement (or a combination of these features). These features include the facts that (1) the cutting edge of the osteotome is squared-off, (2) the taper to the cutting edge of the osteotome blade is less acute than that of the scalpel blade, (3) the cutting edge of the osteotome is curved, which may have deleterious consequences in terms of developing a plane of cleavage through the matrix, and (4) the osteotome has an internal bevel to a closed (circular) system and therefore the tissue at the plug margin is likely to be compressed and subjected to increased abrasion or shear as it is passed through the osteotome.

Measurements of the diameter of the cartilaginous portion of three plugs with use of Vernier calipers suggested that there is considerable expansion of the tissue after removal from the osteotome. It is possible that there may be tissue compression against the edge of the osteotome due to the combination of an internal bevel and a closed (circular) system. After removal from the osteotome, the cartilage expands to its former area. Trauma to the wound edge may cause subsequent swelling in DMEM as a result of osmotic flux into unconstrained glycosaminoglycans. Furthermore, there may be internal stress release following incision, causing tissue expansion.

Recently, Redman et al. ${ }^{14}$ used immature bovine cartilage explants that had been cut off the bone as a model cartilage system with which to compare the effects of trauma caused by a blunt instrument (a trephine) and that caused by a sharp instrument (a scalpel blade). In response to blunt injury, the authors characterized a band of cell death that extended approximately $100 \mu \mathrm{m}$ from the wound edge.

The present study extends previous findings concerning excessive marginal death at the graft edge because it uses the current mosaicplasty technique as a directly relevant surgical paradigm. However, on the basis of our results, we cannot yet designate a particular feature of osteotome design as the cause of marginal cell death. Recently, Evans et al. ${ }^{31}$ compared the effects of two harvest procedures (manual punch and powerharvesting) on chondrocyte viability and documented more damage in the power-trephine group. We are engaged in additional research concerning blade geometry and harvesting in order to identify improvements to minimize chondrocyte death at the graft edge.

In conclusion, we observed a marked marginal zone of cell death (with a thickness of just under $400 \mu \mathrm{m}$ ) in osteochondral plugs within two hours after harvest with use of the mosaicplasty technique. Using a planar model for close-packed circles (see Appendix), we estimated that approximately $24 \%$ of the graft surface is nonviable because of marginal cell death, with an additional 9\% consisting of the gap between plugs. Therefore, approximately one-third of the mosaicplasty surface is not comprised of viable hyaline cartilage. This may be an underestimation given that Hangody et al. ${ }^{7}$ estimated the filling rate for a close-packed circle configuration to be $80 \%$ (as opposed to our calculation of $91 \%)$. Our data suggest that there is scope for improvement of mosaicplasty harvest and graft techniques. This may be reflected in better long-term graft viability, superior integrative repair, and, as a result, improved clinical outcomes.

\section{Appendix}

A detailed description of the planar model is available eA with the electronic versions of this article, on our web site at jbjs.org (go to the article citation and click on "Supplementary Material") and on our quarterly CD-ROM (call our subscription department, at 781-449-9780, to order the CD-ROM).

NOTE: The authors thank Mr. I.J. Brenkel, Mr. R.E. Cook, Ms. J. McEachan, and Mr. T.I.S. Brown (Fife Acute Hospitals) for providing the knee resection specimens; Mr. J. Lissimore for his expert materials and engineering advice and apparatus construction; and Smith and Nephew for kindly providing the mosaicplasty harvest kits free of charge. This project was supported by the Arthritis Research Campaign (H0621) and Wellcome Trust (045925/Z/95/A).

J.S. Huntley, DPhil(Oxon), MRCS

A.H. Simpson, DM(Oxon), FRCS

Musculoskeletal Research Unit, School of Clinical and Surgical Sciences, University of Edinburgh, Teviot Place, Edinburgh EH8 9AG, United Kingdom. E-mail address for J.S. Huntley: jimhuntley@doctors.net.uk

P.G. Bush, $\mathrm{PhD}$

A.C. Hall, $\mathrm{PhD}$

School of Biomedical and Clinical Laboratory Sciences, Hugh Robson Building, George Square, Edinburgh EH8 9XD, United Kingdom

\section{J.M. McBirnie, FRCS}

Department of Orthopaedics, New Royal Infirmary of Edinburgh, Little France, Old Dalkeith Road, Edinburgh EH16 4SA, United Kingdom

In support of their research or preparation of this manuscript, one or more of the authors received grants or outside funding from the Arthritis Research Campaign (H0621) and the Wellcome Trust (045925/Z/95/A). 
The Journal of Bone \& JOINT SURGERY $\cdot$ JBJS.ORG Volume 87-A · Number 2 - February 2005
Chondrocyte Death Associated with Human Femoral Osteochondral Harvest as Performed for Mosaicplasty
None of the authors received payments or other benefits or a commitment or agreement to provide such benefits from a commercial entity. No commercial entity paid or directed, or agreed to pay or direct, any benefits to any research fund, foundation, educational institution, or other charitable or nonprofit organization with which the authors are affiliated or associated. Smith and Nephew provided the mosaicplasty harvest kits free of charge.

doi:10.2106/JBJS.D.02086

\section{References}

1. Hunziker EB. Articular cartilage repair: basic science and clinical progress. A review of the current status and prospects. Osteoarthritis Cartilage. 2002; 10:432-63.

2. Gross AE. Cartilage resurfacing: filling defects. J Arthroplasty. $2003 ; 18$ (3 Suppl 1):14-7.

3. Outerbridge HK, Outerbridge AR, Outerbridge RE, Smith DE. The use of lateral patellar autologous grafts for the repair of large osteochondral defects in the knee. Acta Orthop Belg. 1999;(65 Suppl 1):129-35.

4. Richardson JB, Caterson B, Evans EH, Ashton BA, Roberts S. Repair of human articular cartilage after implantation of autologous chondrocytes. J Bone Joint Surg Br. 1999;81:1064-8.

5. Bentley G, Biant LC, Carrington RW, Akmal M, Goldberg A, Williams AM, Skinner JA, Pringle J. A prospective, randomised comparison of autologous chondrocyte implantation versus mosaicplasty for osteochondral defects in the knee. J Bone Joint Surg Br. 2003;85:223-30.

6. Hangody L, Fules P. Autologous osteochondral mosaicplasty for the treatment of full-thickness defects of weight-bearing joints: ten years of experimental and clinical experience. J Bone Joint Surg Am. 2003;85(Suppl 2):25-32.

7. Hangody L, Rathonyi GK, Duska Z, Vasarhelyi G, Fules P, Modis L. Autologous osteochondral mosaicplasty. Surgical technique. J Bone Joint Surg Am. 2004; 86(Suppl 1):65-72

8. Horas U, Pelinkovic D, Herr G, Aigner T, Schnettler R. Autologous chondrocyte implantation and osteochondral cylinder transplantation in cartilage repair of the knee joint. A prospective, comparative trial. J Bone Joint Surg Am. 2003;85: 185-92.

9. Stockwell RA. Biology of cartilage cells. New York: Cambridge University Press; 1979.

10. Buckwalter JA, Mankin HJ. Articular cartilage. Part I: tissue design and chondrocyte-matrix interactions. J Bone Joint Surg Am. 1997;79:600-11.

11. Mainil-Varlet P, Monin D, Weiler $C$, Grogan $S$, Schaffner T, Zuger B, Frenz M. Quantification of laser-induced cartilage injury by confocal microscopy in an ex vivo model. J Bone Joint Surg Am. 2001;83:566-71.

12. Gilmore RS, Palfrey AJ. Chondrocyte distribution in the articular cartilage of human femoral condyles. J Anat. 1988;157:23-31.

13. Bos PK, DeGroot J, Budde M, Verhaar JA, van Osch GJ. Specific enzymatic treatment of bovine and human articular cartilage: implications for integrative cartilage repair. Arthritis Rheum. 2002;46:976-85.

14. Redman SN, Dowthwaite GP, Thomson BM, Archer CW. The cellular responses of articular cartilage to sharp and blunt trauma. Osteoarthritis Cartilage. 2004;12:106-16.

15. Hunziker EB, Quinn TM. Surgical removal of articular cartilage leads to loss of chondrocytes from cartilage bordering the wound edge. J Bone Joint Surg Am. 2003;85 Suppl 2:85-92.

16. Tew SR, Kwan AP, Hann A, Thomson B, Archer CW. The reactions of articular cartilage to experimental wounding: role of apoptosis. Arthritis Rheum. 2000 43:215-25.

17. Nabavi-Tabrizi A, Turnbull A, Dao Q, Appleyard R. Chondrocyte damage following osteochondral grafting using metal and plastic punches: comparative study in an animal model. J Orthop Surg (Hong Kong). 2002;10:170-2.

18. Lewis JL, Deloria LB, Oyen-Tiesma M, Thompson RC Jr, Ericson M, Oegama TR Jr. Cell death after cartilage impact occurs around matrix cracks. J Orthop Res. 2003;21:881-7.

19. Chen CT, Burton-Wurster N, Borden C, Hueffer K, Bloom SE, Lust G. Chondro cyte necrosis and apoptosis in impact damaged articular cartilage. J Orthop Res. 2001;19:703-11.

20. D'Lima DD, Hashimoto S, Chen PC, Colwell CW Jr, Lotz MK. Human chondrocyte apoptosis in response to mechanical injury. Osteoarthritis Cartilage. 2001; 9:712-9.

21. Aubin PP, Cheah HK, Davis AM, Gross AE. Long-term followup of fresh femo ral osteochondral allografts for posttraumatic knee defects. Clin Orthop. 2001;391 Suppl:S318-27.

22. Brocklehurst R, Bayliss MT, Maroudas A, Coysh HL, Freeman MA, Revell PA, Ali SY. The composition of normal and osteoarthritic articular cartilage from human knee joints. With special reference to unicompartmental replacement and osteotomy of the knee. J Bone Joint Surg Am. 1984;66:95-106.

23. Mitchell $N$, Shepard $N$. The deleterious effects of drying on articular cartilage. J Bone Joint Surg Am. 1989;71:89-95.

24. Bush PG, Hall AC. The volume and morphology of chondrocytes within nondegenerate and degenerate human articular cartilage. Osteoarthritis Cartilage. 2003;11:242-51.

25. Poole $\mathrm{CA}$, Brookes $\mathrm{NH}$, Clover GM. Confocal imaging of the human keratocyte network using the vital dye 5-chloromethylfluorescein diacetate. Clin Experiment Ophthalmol. 2003;31:147-54.

26. Martin JA, Buckwalter JA. Aging, articular cartilage chondrocyte senescence and osteoarthritis. Biogerontology. 2002;3:257-64.

27. Williams SK, Amiel D, Ball ST, Allen RT, Wong VW, Chen AC, Sah RL, Bugbee WD. Prolonged storage effects on the articular cartilage of fresh human osteochondral allografts. J Bone Joint Surg Am. 2003;85:2111-20.

28. Jurvelin JS, Buschmann MD, Hunziker EB. Mechanical anisotropy of the human knee articular cartilage in compression. Proc Inst Mech Eng [H]. 2003;217:215-9.

29. Korhonen RK, Wong M, Arokoski J, Lindgren R, Helminen HJ, Hunziker EB, Jurvelin JS. Importance of the superficial tissue layer for the indentation stiffness of articular cartilage. Med Eng Phys. 2002;24:99-108.

30. Below S, Arnoczsky SP, Dodds J, Kooima C, Walter N. The split-line pattern of the distal femur. A consideration in the orientation of autologous cartilage grafts. J Arthrosc Rel Res. 2002;18:613-7.

31. Evans PJ, Miniaci $A$, Hurtig MB. Manual punch versus power harvesting of osteochondral grafts. Arthroscopy. 2004;20:306-10. 